\title{
Challenges and Opportunities for Tourism Development in Iran: Perspectives of Iranian Tourism Suppliers
}

\begin{abstract}
Iranian tourism industry - despite enormous potentials - has faced a number of challenges including wide ranging nuclear related sanctions, negative imagery in the west and lack of effective management of resources. The aim of this paper is to focus on the perspectives of Iranian tourism suppliers who have a crucial role in the development and success of the tourism industry in the country. The findings of this paper are based on interviews conducted in Iran with representatives of Iranian tourism suppliers from both the public and private sector. The analysis of these interviews suggests that tourism suppliers face two major challenges: (1) Iran's negative imagery in the West and (2) lack of resources to tackle this negative discourse. This paper also provides an overview of the potential future opportunities which the recently forged nuclear agreement could present for Iranian tourism suppliers.
\end{abstract}

Key words: Destination image; destination development; Iran tourism; Iran nuclear; tourism suppliers; tourism development

\section{Introduction}

Iran is a country with substantial tourism potentials. One of the UK's most influential newspapers, The Financial Times, claims that 'Iran is undoubtedly a blessed country. In addition to its vast reserves of natural resources, its vibrant culture makes it so much more than just another resource-rich developing economy’ (Financial Times, 2016). The recent nuclear agreement - reached in Vienna on 14 July 2015 - and the subsequent softening of relations with the west has opened the door to a brighter future for the country (Khodadadi, 2016). However, Iran's tourism industry has been suffering from a range of issues over the past three decades, including the over-reliance on oil revenues, negative imagery, international sanctions, political instability and conflicts in the Middle East region, and poor management (Khodadadi, 2016). This paper focuses on two main 'challenges' from the Iranian tourism suppliers' perspective: (1) Iran's negative imagery in the tourist generating markets and (2) the lack of essential resources needed to counter the negative discourse and promote the country in the international market. 


\section{Interviews with Iranian Tourism Suppliers}

To understand the perspectives of Iranian tourism suppliers, a total of six semi-structured interviews were conducted during a field-trip to Tehran, Iran, in June 2010. Participants were selected based on their roles within the Iranian tourism industry at the time when interviews were conducted.

\subsection{The Public Sector}

Interviewee One: A high ranking civil servant within the Bureau of Planning and Development of International Tourism at the Iran Cultural Heritage, Tourism and Handicraft Organisation. This organisation is a governmental body responsible for the planning and development of tourism.

Interviewee Two: A representative of Cultural Heritage and Tourism Exhibition Company. This Company is part of the ICHTHO and is responsible for and runs Iran's stand at international tourism exhibitions such as World Travel Market, ITB, BIT, ATM, etc.

These individuals were - at the time when interviews were conducted - leading figures within the two and only main public-sector organisations primarily responsible for the development of the international tourism market for Iran. Hence, they have the key responsibility of producing and supplying 'induced’ information sources (Gartner, 1994) in the potential target markets and, therefore, have a vital role in the production and circulation of destination images.

\subsection{The Private Sector}

Interviewee Three: A high level member of Iran and Tehran Travel and Tourism Union, also known as the Iranian Tour Operators Association (ITOA).

Interviewee Four: A Member of the Board of Directors at Tehran Tour and Travel Agencies Associations.

Interviewee Five: Managing Director of Tour Operator A.

Interviewee Six: Managing Director of Tour Operator B. 
Participants 4, 5 and 6 are the leaders of three major tour operators in Iran specialised in inbound tourism from western countries. Interviewee 3, a high level member of Iran and Tehran Travel and Tourism Union was also selected because of his fundamental role in facilitating collaboration between the public and private sector and his substantial knowledge of the development of the private sector, policies, planning, performance and the tourism industry in Iran in general. These individuals were - at the time when interviews were conducted - key representatives of the private sector as they are highly active in the development of the international tourism market for Iran.

\section{Perspectives of Iranian Tourism Suppliers}

\subsection{Challenges of The Negative Imagery}

Analysis of the interviews shows that the tourism suppliers were acutely aware of the current negative imagery of Iran in Western countries and were eager to project Iran as what in their minds it actually is, in other words what they see as the 'real' or 'everyday Iran' rather than the political Iran projected by the foreign media (Khodadadi \& O’Donnell, 2015). When asked what images they were trying to transmit to external tourists their responses were clearly framed within a discourse of ontological truth centred on culture and society:

We are trying to tell the truth about Iran to people around the world. This depends on firstly erasing the current negative image created in people's minds and then introducing the true Iran (Interviewee 2).

The frustrations they feel in this endeavour are repeatedly signalled through the use of modal terms such as 'need to’, ‘try’, ‘would like to’:

We need to transmit true images of Iran and the real Iran to external tourists (Interviewee 1).

We are trying to transmit real and true images of Iran to foreign tourists (Interviewee 6).

The image that we would like to transfer is a real image of Iran and its culture and society (Interviewee 5). 
Here we can clearly see that Iranian suppliers are trying to distance Iran from the media produced and heavily politicised discourse/image of Iran (Jalilvand et al., 2012; Khodadadi \& O’Donnell, 2015). They are instead keen to associate the ‘everyday Iran' discourse of Iran with a place that has friendly people, is civilised and peace-loving. The analysis shows that the tourism suppliers are particularly keen to promote Iran as a 'hospitable' country as well as the desire to distance Iran from any association with dominant notions of 'Arab country'.

The most important image that we would like to transmit is the hospitality of Iranian people (Interviewee 4).

They realise that Iranians are nice, hospitable and Iran is not a third world Arab country (Interviewee 5).

The discourse of 'hospitality' is a key discourse amongst suppliers and one they are particularly keen to transmit to external tourists. For them this is the real Iran since they hold the notion of 'hospitality' to be deeply rooted in Iranian culture.

\subsection{Challenges of the Lack of Resources}

Interviews with the suppliers reveals that there is - or at least was at the time of the interviews - a significant lack of political support for and investment in how suppliers disseminate desired discourses/images of Iran, a lack which was occasionally contrasted with the situation in other countries:

Our biggest problem is to secure our costs. Many of the things we do are not even as much as the budget for a month in other countries. The private sector is also weak in terms of investment although in many other countries it is the private sector that invests the most (Interviewee 2).

Here in our organisation we have limited financial resources because the tourism industry in its modern form is a new phenomenon in Iran. It means that we are behind many other countries that started their tourism developments earlier, such as Turkey. Therefore, we have very limited financial resources and I can say that 
the entire budget of the Iranian tourism organisation could be less than $10 \%$ of Turkey’s budget in different tourism development activities. (Interviewee 1).

A clear example of this - particularly with reference to the last statement above - can be seen from the Table below (Table 1) which shows that while Turkey's capital investment in tourism in 2013 was $\$ 18.5$ billion, Iran’s only reached \$4.1 billion (WTTC, 2014).

\begin{tabular}{|l|r|r|r|r|r|r|r|r|c|}
\hline $\begin{array}{l}\text { Capital } \\
\text { Investment } \\
\text { US\$ bn }\end{array}$ & $\mathbf{2 0 0 5}$ & $\mathbf{2 0 0 6}$ & $\mathbf{2 0 0 7}$ & $\mathbf{2 0 0 8}$ & $\mathbf{2 0 0 9}$ & $\mathbf{2 0 1 0}$ & $\mathbf{2 0 1 1}$ & $\mathbf{2 0 1 2}$ & $\mathbf{2 0 1 3}$ \\
\hline Iran & 1.86 & 2.03 & 2.49 & 3.28 & 3.22 & 3.233 & 3.773 & 3.803 & 4.166 \\
\hline Turkey & 9.39 & 9.41 & 8.32 & 11.3 & 1109 & 10.32 & 17.326 & 16.941 & 18.523 \\
\hline
\end{tabular}

Table 1. Capital Investment in Tourism Iran vs. Turkey (Source: WTTC, 2014)

The supplier's inability to provide an alternative source of information for potential tourists, however limited, has also contributed to some extent to the media becoming the dominant or even for many people the only source of information in external tourist markets (Khodadadi \& O’Donnell, 2015). This is not helped by the fact that even those small-scale Iranian efforts that have been invested in promotion strategies have not been effective in reaching the target audience. Majority of the investment by the public and private sector is going into the development and production of brochures and catalogues and participation in international exhibitions with very little attention to the recent developments in Information and Communication Technologies and particularly the Internet.

\section{Conclusion}

It is clear that Iranian tourism suppliers have a clear understanding of Iran's image problems and have a clear vision of how they would like to promote Iran in the tourist generating markets (as a hospitable, peace-loving and generous nation). However, after speaking to suppliers from both the public and private sector it is very much evident that little effort has been invested in the development and delivery of sufficient 'induced' sources to assist the production and circulation of desired images in the tourist generating markets. Future however, looks more promising particularly since the 14 July 2015 nuclear deal and the consequent easing of the international sanctions against the country (Khodadadi, 2016). For instance, the director of 
Iran's Cultural Heritage, Handicrafts and Tourism Organization claims that 'Iran plans to annually attract 20 million tourists by 2025 which could generate $\$ 30$ billion of revenues' (Press TV, 2015). Although this could be seen as an optimistic estimation, the recent reports on the level of interest by foreign investors (Euromonitors, 2015; Press TV, 2015) to enter Iran's untouched market tells a similar story. Murphy (2016) of the UK's Financial Times for instance claims that 'Iran will be the largest economy to re-enter international markets since the fall of the Soviet Union'. Government's change of attitude towards tourism is also evident through increase in the length of tourist visas from 15 days to one month, and visa on arrival for a large number of nationalities. These in turn presents a unique opportunity for the Iranian tourism suppliers from both the public and private sector to work as a unified force to promote and unlock Iran's untouched and unique tourism potentials and pursue a better future for the Iranian tourism industry.

\section{References}

Euromonitor International (2015). Travel and tourism in Iran report. Retrieved from: https://www.portal.euromonitor.com/, December 8.

Financial Times (2016). FT Iran Summit: Exploring Opportunity and Risk in a Potential Economic Powerhouse. Retrieved from: https://live.ft.com/Events/2016/FT-IranSummit-2016, March 9.

Gartner, C. W. (1994). Image Formation Process, Journal of Travel \& Tourism Marketing, 2 (2), 191-216.

Jalilvand, M. R., Samiei, N., Dini, B., \& Manzari, P. Y. (2012). Examining the structural relationships of electronic word of mouth, destination image, tourist attitude toward destination and travel intension: An integrated approach. Journal of Destination Marketing \& Management, 1, 134-143.

Khodadadi, M. (2016). A new dawn? The Iran nuclear deal and the future of the Iranian tourism industry. Tourism Management Perspectives, 18, 6-9. DOI: http://dx.doi.org/10.1016/j.tmp.2015.12.019

Khodadadi, M. \& O’Donnell, H. (2015). UK press and tourist discourses of Iran: a study in multiple realities, Leisure Studies, DOI: http://dx.doi.org/10.1080/02614367.2015.1085591 
Murphy, H. (2016). Iran is back in business. The Financial Times, Retrieved from: http://www.ft.com/cms/s/0/325fdf4a-bec6-11e5-846f-

79b0e3d20eaf.html\#axzz43p26jEiy, January 29.

Press TV (2015). Iran tourism catches eye of big hoteliers. Retrieved from http://www.presstv.ir/Detail/2015/05/30/413490/iran-tourism-hotels-investment, May 30.

World Travel and Tourism Council (2014). Economic data search. Retrieved from http:// www.wttc.org/research/economic-data-search-tool/, December 24. 